\title{
Intestinal epithelial Toll-like receptor 4 prevents metabolic syndrome by regulating interactions between microbes and intestinal epithelial cells in mice
}

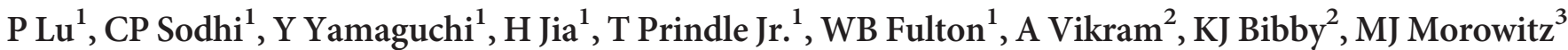 \\ and DJ Hackam ${ }^{1}$
}

Little is known about the pathogenesis of metabolic syndrome, although Toll-like receptor 4 (TLR4) has been implicated. We investigated whether TLR4 in the intestinal epithelium regulates metabolic syndrome by coordinating interactions between the luminal microbiota and host genes that regulate metabolism. Mice lacking TLR4 in the intestinal epithelium $\left(T_{2 R}{ }^{\Delta I E C}\right)$, but not mice lacking TLR4 in myeloid cells nor mice lacking TLR4 globally, developed metabolic syndrome; these features were not observed in TLR $4^{\Delta \mathrm{IEC}}$ mice given antibiotics. Metagenomic analysis of the fecal microbiota revealed differences between TLR4 $4^{\Delta \mathrm{IEC}}$ and wild-type mice, while meta-transcriptome analysis of the microbiota showed that intestinal TLR4 affected the expression of microbial genes involved in the metabolism of lipids, amino acids, and nucleotides. Genes regulated by peroxisome proliferator-activated receptors (PPARs) and the antimicrobial peptide lysozyme were significantly downregulated in TLR4 ${ }^{\triangle \mathrm{IEC}}$ mice, suggesting a mechanism by which intestinal TLR4 could exert its effects on the microbiota and metabolic syndrome. Supportingly, antibiotics prevented both downregulation of PPAR genes and the development of metabolic syndrome, while PPAR agonists prevented development of metabolic syndrome in TLR4 ${ }^{\mathrm{SIEC}}$ mice. Thus, intestinal epithelial TLR4 regulates metabolic syndrome through altered hostbacterial signaling, suggesting that microbial or PPAR-based strategies might have therapeutic potential for this disease.

\section{INTRODUCTION}

Metabolic syndrome refers to a cluster of disorders including abdominal obesity, glucose intolerance, and hepatic steatosis, and is an important cause of morbidity and mortality. While the precise causes of metabolic syndrome remain incompletely understood, genetic ${ }^{2}$, dietary, ${ }^{3}$ and microbial factors ${ }^{4}$ have each been recognized to play a role in its pathogenesis. The importance of bacteria in the development of metabolic syndrome is supported by the striking observation that the administration of antibiotics prevents its development in mice, ${ }^{5,6}$ while the transfer of bacteria from obese mice or humans to lean mice induces metabolic syndrome in recipient mice. ${ }^{7,8}$ From the point of view of the host, polymorphisms in the receptor for Gram-negative bacterial endotoxin, namely Toll-like receptor 4 (TLR4), have been associated with an increased risk for the development of metabolic syndrome and obesity in humans, ${ }^{9}$ and patients with metabolic syndrome show increased TLR4 expression in monocytes. ${ }^{10,11}$ The endotoxin receptor complex consists of TLR4, CD14, and $\mathrm{MD}-2$, and this complex signals in response to either the myeloid differentiation primary response gene 88 (MyD88)dependent pathway, which is critical for the production of several pro-inflammatory cytokines, or the MyD88-independent pathway, which depends on the TIR domain containing

${ }^{1}$ Division of General Pediatric Surgery, Johns Hopkins University and Bloomberg Children's Center, Johns Hopkins Hospital, Baltimore, Maryland, USA. ²Department of Civil and Environmental Engineering, University of Pittsburgh, Pittsburgh, Pennsylvania, USA and ${ }^{3}$ Department of Surgery, University of Pittsburgh School of Medicine, Pittsburgh, Pennsylvania, USA. Correspondence: DJ Hackam (dhackam1@jhmi.edu) 
adaptor inducing interferon-beta (TRIF) signal adaptor protein and is crucial for type I interferon production. ${ }^{12,13}$ In mice receiving a high-fat diet, TLR4-deficient mice show either reduced $^{14}$, unaffected, ${ }^{15}$ or increased ${ }^{16}$ risk for the development of metabolic syndrome compared with wild-type counterparts. The apparent discrepancy in the findings regarding the role for TLR4 in the development of metabolic syndrome has proven to be a source of significant controversy in the field, and point to a greater need to understand the impact of host-microbial interactions in its pathogenesis. One possible explanation for the varying results may lie in the fact that TLR4 signaling in various different cells-for example the myeloid cells vs. the intestinal epithelial cells-could exert different, and perhaps even opposite, effects on the development of metabolic syndrome.

We now seek to address this controversy by testing the hypothesis that the expression of TLR4 in the intestinal epithelium as opposed to other cell types plays a critical role in the development of metabolic syndrome by coordinating the interaction between the luminal microbiota and genes that regulate metabolically important pathways in the host.

\section{RESULTS}

\section{Intestinal epithelial TLR4 expression regulates the development of metabolic syndrome in mice}

To evaluate the role of intestinal epithelial TLR4 in the development of metabolic syndrome, we first administered standard chow, containing $22 \%$ calories as fat, to mice harboring floxed alleles of TLR4 (wild-type) or to age- and gender-matched mice in which TLR4 was selectively deleted from the intestinal epithelium (TLR $4^{\triangle I E C}$ ), from the ages of 324 weeks. We observed that despite being fed standard chow, when compared with floxed wild-type mice, TLR4 ${ }^{\Delta \mathrm{IEC}}$ mice developed a constellation of symptoms consistent with metabolic syndrome, ${ }^{1,17}$ which included significant weight gain $(38.64 \pm 3.829 \mathrm{~g}$ vs. $43.08 \pm 3.970 \mathrm{~g}, P<0.05$ over 21 weeks) (Figure 1a), and increased weight of adipose tissue and liver (Figure 1b). The differences in weight gain between wild-type and TLR4 ${ }^{\triangle \mathrm{IEC}}$ mice strains became noticeable at approximately 12 weeks of age, and became significantly different from wild-type mice at 24 weeks of age (Figure 1ai). The increased body weight in TLR $4{ }^{\triangle I E C}$ mice did not depend on food intake (Supplementary Figure 1A online), nor hormone levels that regulate appetite since both strains had similar serum leptin and ghrelin expression (Supplementary Figure 1B). Other markers of metabolic syndrome were also observed in the TLR4 ${ }^{\triangle \mathrm{IEC}}$ but not wild-type mice, including "hepatocellular ballooning" which indicates the accumulation of fat droplets within hepatocytes (Figures 2a and b), a trend towards increased liver triglycerides (Supplementary Figure 1C), the histologic presence of "crown-like structures" within the adipose tissue (Figure 2c) indicating the accumulation of macrophages, ${ }^{18}$ and the increased expression of macrophage markers (F4/80 and Cd68) and the pro-inflammatory M1 phenotype macrophage markers (Tnf and $C d 11 c$ ), but not the anti-inflammatory M2 phenotype macrophage marker (Retnlb), in the adipose tissue at the age of 24 weeks (Figure 2d).
We noted that there was no difference observed in the size of the adipocytes between strains (Supplementary Figure 1D). Despite similar serum insulin (Supplementary Figure 1E), TLR4 ${ }^{\triangle I E C}$ mice but not wild-type counterparts displayed significant insulin resistance, as measured by significant hyperglycemia after the administration of an oral glucose challenge at the age of 24 weeks (Figure 2e). There were no differences in serum cholesterol (Supplementary Figure 1F), serum triglycerides (Supplementary Figure 1G), and serum endotoxin content (Supplementary Figure 1H). Taken together, these findings illustrate that the lack of TLR4 on the intestinal epithelium leads to the development of metabolic syndrome in mice.

Given that many studies examining the development of metabolic syndrome in mice have utilized a high-fat diet, whereas the above data were observed in the presence of a "standard" diet, we next administered a high-fat diet in which $60 \%$ of the total calories are derived from fat to wild-type and TLR $4^{\triangle \mathrm{IEC}}$ mice from the age of 3-12 weeks. As shown in Supplementary Figure 2A, on a high-fat diet, TLR4 ${ }^{\triangle \mathrm{IEC}}$ mice still gained significantly more weight than wild-type mice ( $40.96 \pm 5.061 \mathrm{~g}$ vs. $35.57 \pm 3.423 \mathrm{~g}, P<0.05$ over 9 weeks), and the weight gain was observed at much earlier time points as compared with mice that were fed standard chow ( 3 weeks for a high-fat diet vs. 9 weeks for those fed standard chow). Further, although 12 -week-old TLR4 ${ }^{\Delta \mathrm{IEC}}$ mice fed standard chow started to show significantly increased body weight (Figure 1ai), there was no difference between wild-type and TLR4 $4^{\Delta I E C}$ mice in glucose tolerance (Supplementary Figure 3). On the contrary, 12-week-old TLR $4^{\Delta \mathrm{IEC}}$ mice who were fed a high-fat diet also showed impaired glucose tolerance as compared with age-matched wild-type mice fed high-fat diet (Supplementary Figure 2B). Moreover, 12-week-old TLR $4^{\Delta \mathrm{IEC}}$ mice fed highfat diet showed an increased accumulation of adipose tissue (inguinal fat and mesenteric fat) and increased liver weight (Supplementary Figure 2C), elevated serum cholesterol (Supplementary Figure 2D), but similar serum triglycerides (Supplementary Figure 2E) as compared with wild-type mice, supportive of our findings that the lack of TLR4 on the intestinal epithelium results in the development of significant weight gain, insulin resistance and other features of metabolic syndrome regardless the fat content of the diet.

To confirm the role of intestinal epithelial TLR4 expression on metabolism, we next studied two additional TLR4 transgenic mouse strains, namely TLR $4^{\mathrm{IEC}-o n l y}$ mice in which TLR4 is expressed only in the intestinal epithelial cells, and TLR$^{-1-}$ mice that are globally TLR4 deficient. As shown in Figures 1a and $\mathbf{b}$, the administration of standard chow containing $22 \%$ calories from fat to both TLR4 ${ }^{-1-}$ and TLR4 ${ }^{\text {IEC-only }}$ resulted in similar total body weight, as well as the weight of adipose tissue and liver, compared with wild-type mice at 24 weeks of age. Similarly, TLR4 ${ }^{-1-}$ and TLR4 $4^{\mathrm{IEC}-\text { only }}$ mice displayed equivalent glycemic curves after a bolus of glucose compared with wild-type mice (Figure 2e). Of note, although the inguinal and mesenteric fat content is higher in the TLR4 ${ }^{\triangle \mathrm{IEC}}$ mice compared with the wild-type and the TLR $4^{-1-}$ mice, there are no 
a i

Body weight

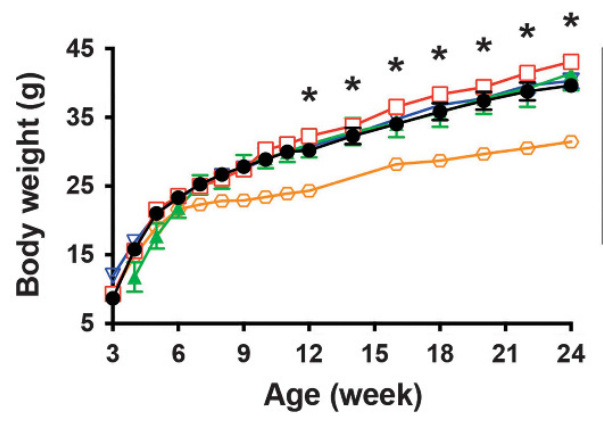

ii Body weight, 24 weeks

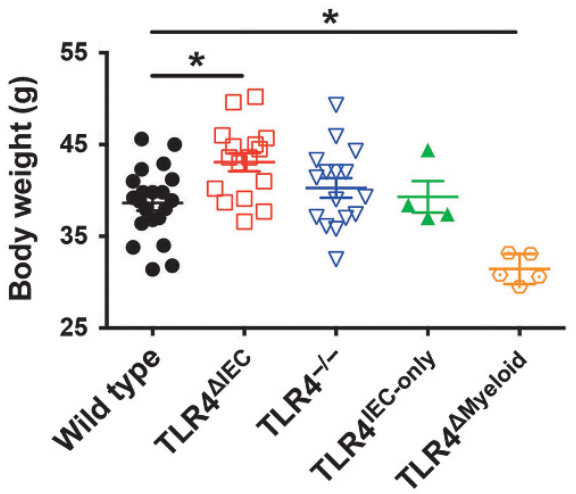

iii

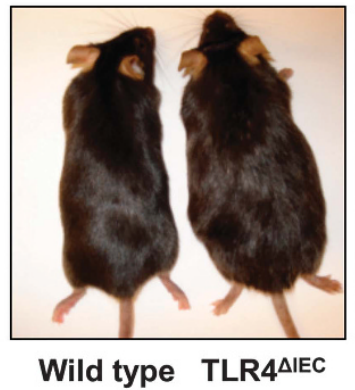

- Wild type

$\square$ TLR4 $\triangle$ IEC

$\nabla \mathrm{TLR}^{-1-}$

$\triangle$ TLR4 ${ }^{\text {IEC-only }}$

ค TLR4 $\triangle$ Myeloid
Whole body photograph

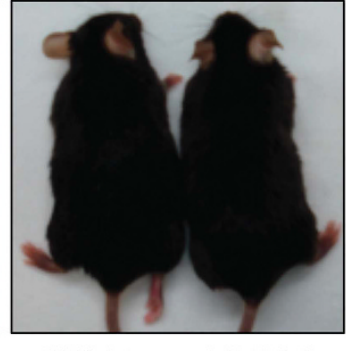

Wild type TLR4 $^{-/-}$

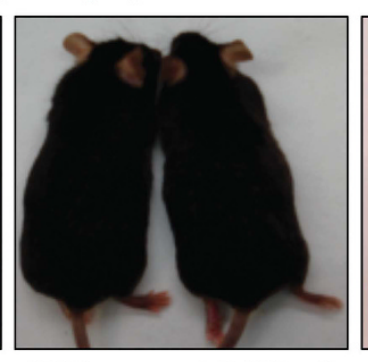

Wild type TLR4IEC-only

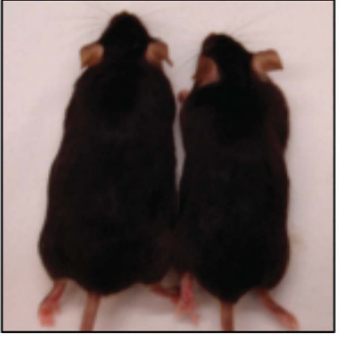

Wild type TLR4 ${ }^{\Delta \text { Myeloid }}$

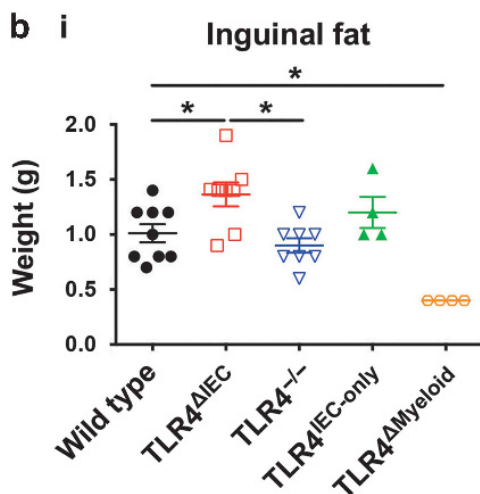

iv
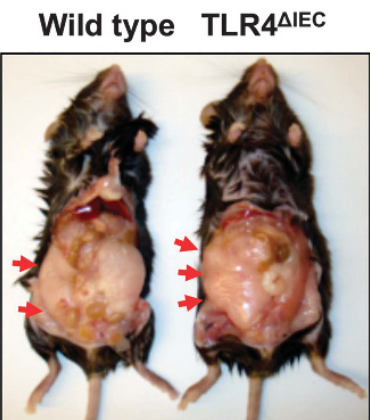

ii

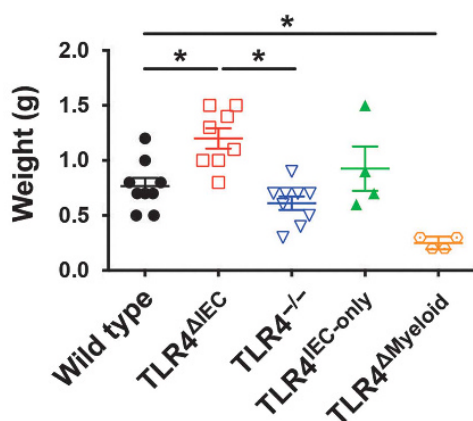

V

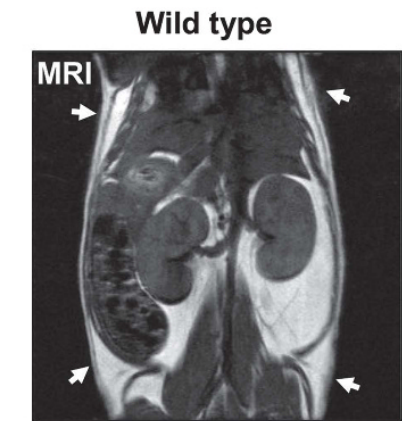

iii

Liver

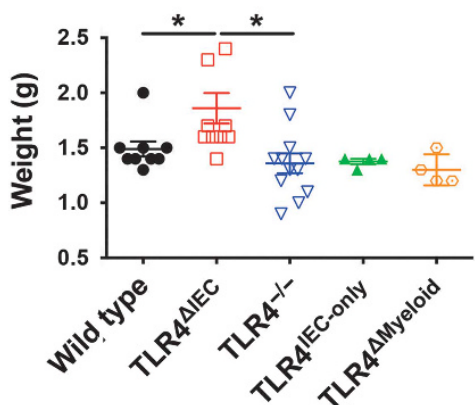

TLR4 ${ }^{\Delta I E C}$

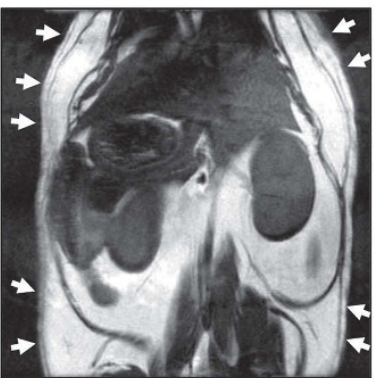

Figure 1 Deletion of the lipopolysaccharide receptor TLR4 from intestinal epithelial cells leads to obesity in mice. (a) (i) Determination of body weight between 3 and 24 weeks of wild-type $(n=33)$, TLR $4^{\Delta \mathrm{IEC}}(n=31)$, TLR $4^{-1-}(n=31)$, TLR $4^{\mathrm{IEC}-o n l y}(n=6)$, and TLR4 $4^{\Delta \text { Myeloid }}(n=8)$ mice who were fed standard chow; (ii) body weight at 24 weeks for the wild-type $(n=21), \operatorname{TLR}^{\Delta \mathrm{IEC}}(n=16), \operatorname{TLR}^{-1-}(n=16)$, TLR4 $4^{\mathrm{IEC}-\text { only }}(n=4)$, and TLR4 ${ }^{\Delta \mathrm{Myeloid}}(n=5)$ mice is shown. Data are represented as mean \pm s.e.m.; ${ }^{*} P<0.05$ wild-type vs. TLR4 ${ }^{\Delta \mathrm{IEC}}$ mice at the indicated time point; each symbol represents a separate mouse; (iii) representative photographs of wild-type, TLR4 ${ }^{\Delta \mathrm{ECC}}, \mathrm{TLR}^{-l-}, \mathrm{TLR}^{\mathrm{IEC}-o n l y}$, and TLR4 ${ }^{\Delta M y e l o i d}$ at 24 weeks of age is shown revealing the significantly larger size of the TLR4 ${ }^{\Delta I E C}$ mice compared with wild-type mice. (b) Weight of inguinal fat (i), mesenteric fat (ii) and liver (iii) of wild-type $(n=9), \operatorname{TLR}^{\Delta I E C}\left(n=8-10\right.$ as indicated), TLR4 ${ }^{-1-}\left(n=8-12\right.$ as indicated), TLR4 ${ }^{\text {lEC-only }}(n=4)$, and TLR4 ${ }^{\Delta \text { Myeloid }}(n=4)$ mice fed standard chow at the age of 24 weeks. Data are represented as mean \pm s.e.m.; ${ }^{*} P<0.05$ for the indicated comparison; each symbol represents a separate mouse; (iv, v) representative photograph (iv) and micro-MRI (v) revealing increased abdominal fat in the TLR4 ${ }^{\Delta I E C}$ as compared with wild-type mice at 24 weeks of age; arrows show the deposition of adipose tissue in the subcutaneous tissue. TLR4, Toll-like receptor 4. 
a

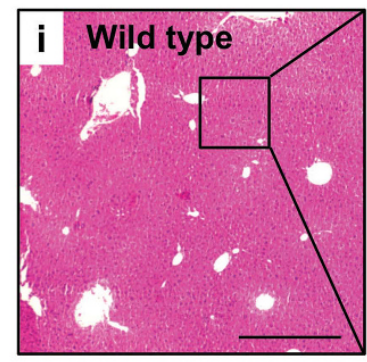

b

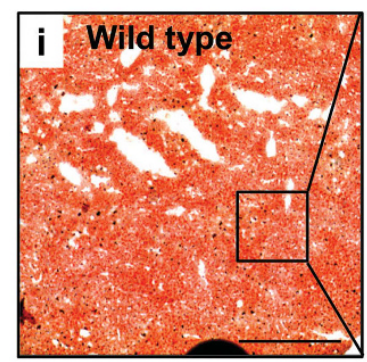

C

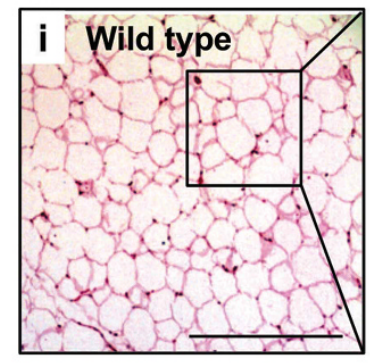

d

Adipose tissue

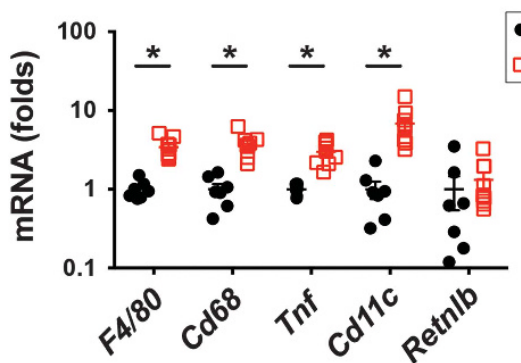

Liver H\&E
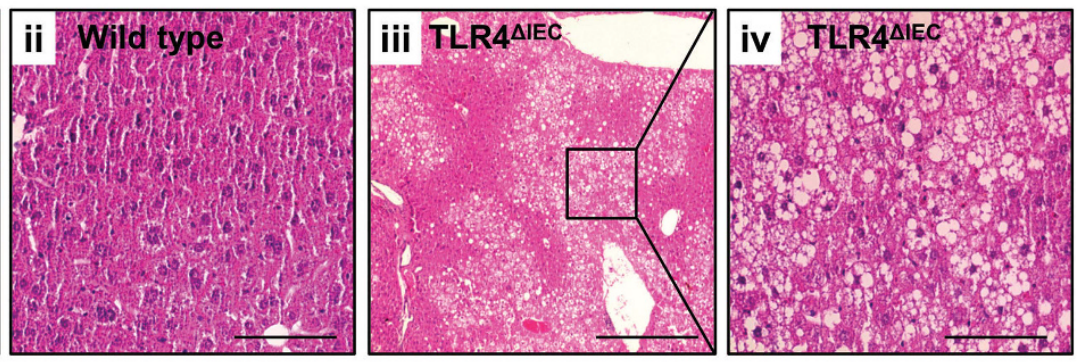

Liver oil red 0
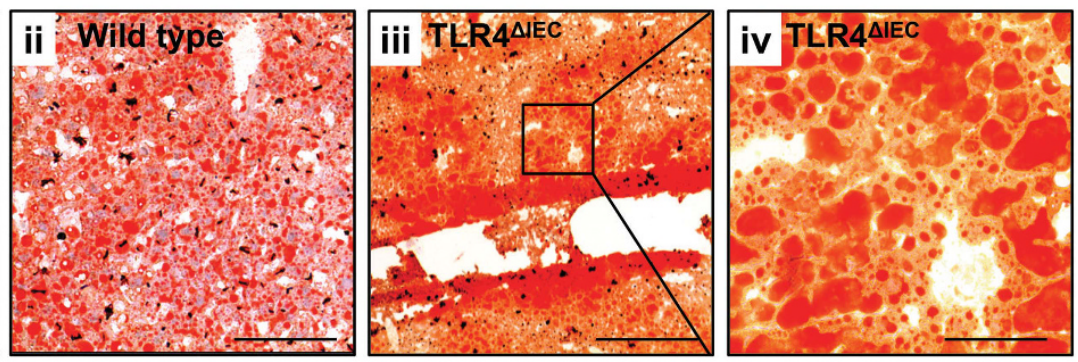

Adipose tissue H\&E
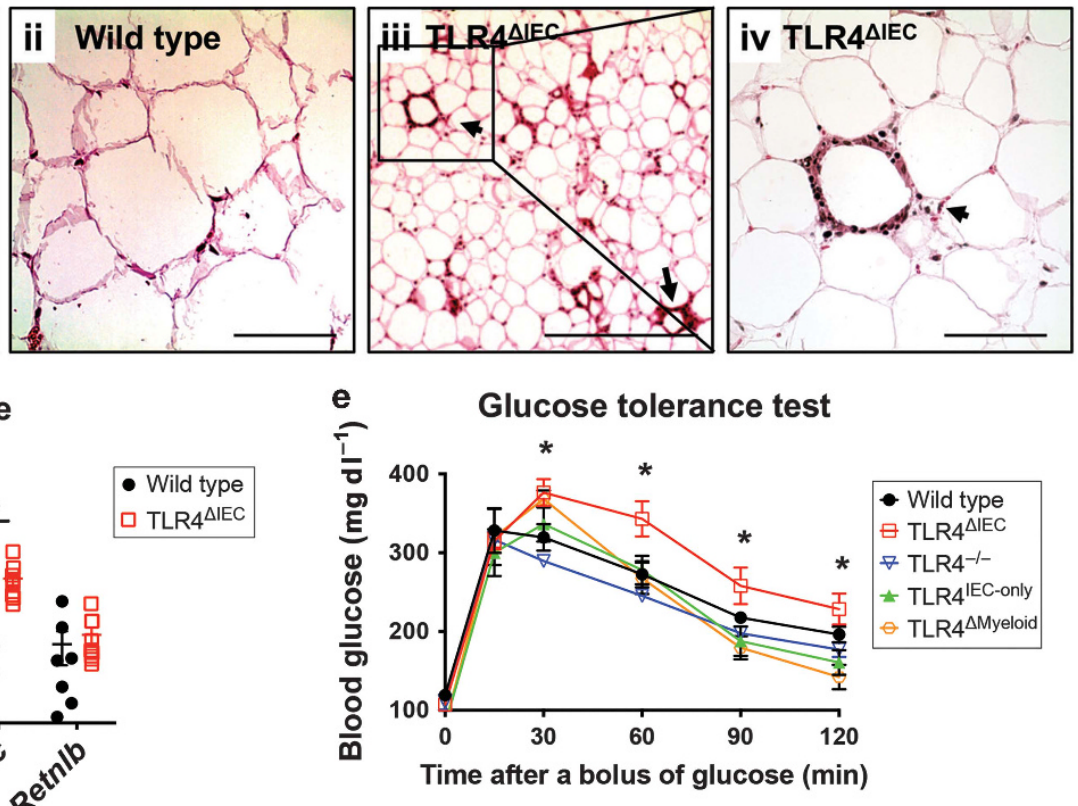

Figure 2 Determinants of metabolic syndrome in mice lacking TLR4 from the intestinal epithelium. (a) Representative photomicrographs showing liver sections of wild-type mice (i and ii) and TLR $4^{\Delta I E C}$ mice (iii and iv) fed standard chow at the age of 24 weeks, which were stained with hematoxylin and eosin. Scale bars represent $400 \mu \mathrm{m}$ and $100 \mu \mathrm{m}$ in the $\times 10$ (i and iii) and $\times 40$ (ii and iv) panels, respectively. (b) Representative photomicrographs showing liver sections of wild-type mice ( $\mathrm{i}$ and ii) and TLR $4^{\Delta \mathrm{IEC}}$ mice (iii and iv) fed standard chow at the age of 24 weeks, which were stained with oil red $\mathrm{O}$. Scale bars represent $400 \mu \mathrm{m}$ and $100 \mu \mathrm{m}$ in the $\times 10$ (i and iii) and $\times 40$ (ii and iv) panels, respectively. (c) Representative photomicrographs showing white adipose tissue sections of wild-type mice ( $\mathrm{i}$ and ii) and TLR4 ${ }^{\triangle \mathrm{IEC}}$ mice (iii and iv) fed standard chow at the age of 24 weeks, which were stained with hematoxylin and eosin. Arrows point to crown-like structure in the white adipose tissue of TLR4 ${ }^{\Delta \mathrm{IEC}}$ mice, and scale bars represent $400 \mu \mathrm{m}$ and $100 \mu \mathrm{m}$ in the $\times 10$ (i and iii) and $\times 40$ (ii and iv) panels, respectively. (d) qPCR showing the expression of the indicated macrophage markers in the white adipose tissues of wild-type $(n=7)$ and TLR4 ${ }^{\Delta I E C}(n=9)$ mice fed standard chow at the age of 24 weeks. All data were normalized to the mRNA expression of $R p / p 0$, and the mRNA expression in wild-type mice was set to 1. Data are represented as mean \pm s.e.m.; ${ }^{*} P<0.05$ between groups shown; each symbol represents a separate mouse. (e) Oral glucose tolerance test of wild-type $(n=12)$, TLR4 ${ }^{\Delta \mathrm{IEC}}(n=9)$, TLR $4^{-1-}(n=5)$, TLR4 $4^{\mathrm{IEC}-o n l y}(n=4)$, and $\operatorname{TLR} 4{ }^{\Delta \text { Myeloid }}(n=4)$ mice fed standard chow at the age of 24 weeks. Data are represented as mean \pm s.e.m.; ${ }^{*} P<0.05$ wild-type vs. TLR4 ${ }^{\Delta I E C}$ mice. TLR4, Toll-like receptor 4; qPCR, quantitative PCR.

differences in the other parameters among all the other strains, and in particular there are no differences in fat depositions between the TLR4 ${ }^{\triangle \mathrm{IEC}}$ and TLR4 ${ }^{\mathrm{IEC}-o n l y}$ mice.
Given that TLR $4^{\triangle \mathrm{IEC}}$ mice showed increased weight gain and the development of metabolic syndrome, we next investigated further the observation that TLR4 ${ }^{-1-}$ mice did not develop 
metabolic syndrome, suggesting that the lack of TLR4 on some cells may have opposing effects in the development of metabolic syndrome than its expression on other cells. We therefore next hypothesized that TLR4 expression on myeloid cells plays an opposite role to that on the intestinal epithelium in the regulation of host metabolism. To test this possibility directly, we subjected mice in which TLR4 was selectively deleted from myeloid cells (TLR4 ${ }^{\Delta \text { Myeloid }}$ ) mice to the same standard chow above, and observed that at 24 weeks, TLR4 ${ }^{\Delta \text { Myeloid }}$ mice did not develop significant weight gain (Figures 1a and b), and had a similar glycemic curve to TLR4 ${ }^{-1-}$ mice and wild-type mice after a glucose bolus (Figure 2e). These findings indicate that deletion of TLR4 from the intestinal epithelium as opposed to other cell types is required for the development of metabolic syndrome in mice, and we next sought to explore the mechanisms involved by focusing on the intestinal microbiota.

\section{The administration of broad spectrum oral antibiotics or co- housing with wild-type mice prevented the development of metabolic syndrome in TLR4 ${ }^{\Delta I E C}$ mice}

Given that TLR4 is a receptor for bacterial endotoxin, we next hypothesized that the effects of intestinal epithelial TLR 4 on the regulation of host metabolism could be mediated in part by an effect on the intestinal microbiota. To test this possibility directly, we orally administered broad spectrum antibiotics to either wild-type or TLR $4^{\Delta \mathrm{IEC}}$ mice which were fed standard chow. The antibiotic treatment was determined to significantly reduce the bacterial load within the intestinal tract as shown in Supplementary Figure $\mathbf{4 A}$, and prevented the previously observed excess weight gain observed in the TLR $4^{\Delta \mathrm{IEC}}$ strains, which were now found at similar body weights throughout the 24-week period to wild-type mice (Figure 3a) and did not show excess weight gain of the adipose tissue and liver (Figure $\mathbf{3 b}$ ). The administration of antibiotics also prevented the previously observed hepatocellular ballooning (Figures $\mathbf{3 c}$ and $\mathbf{d}$ ) and the presence of crown-like structures in the adipose tissue (Figure $3 \mathbf{e})$, and abrogated changes in expression of the macrophage genes in the adipose tissues (Figure 3f). Most strikingly, the administration of oral broad spectrum antibiotics prevented the previously observed glucose intolerance in the TLR4 ${ }^{\triangle I E C}$ mice seen after a glucose bolus (Figure 3g). These findings point to an important role for the microbiota in the development of metabolic syndrome in the TLR4 ${ }^{\Delta \mathrm{IEC}}$ mice.

To further evaluate the hypothesis that the effects of intestinal epithelial TLR4 on the regulation of host metabolism could be mediated through effects on the intestinal microbiota, we co-housed TLR $4^{\triangle I E C}$ mice and wild-type mice together after weaning, and supplied standard chow until 24 weeks of age. Importantly, co-housing resulted in similar body weight gain (Supplementary Figure 4B), similar weight of adipose tissue and liver (Supplementary Figure 4C), and similar glucose tolerance (Supplementary Figure 4D) between TLR $4^{\Delta \mathrm{IEC}}$ mice and wild-type mice, and completely reversed the previously observed metabolic syndrome phenotype. Taken together, these findings support a role for the microbiota in the pathogenesis of metabolic syndrome in the TLR $4^{\Delta \mathrm{IEC}}$ mice, leading us to next evaluate the effects of TLR4 on the composition and function of the intestinal microbiota in greater detail.

\section{Intestinal epithelial TLR4 influences the composition and} function of the intestinal microbiota in mice

To further explore the role of intestinal epithelial TLR4 on the development of metabolic syndrome, we next subjected stool samples from TLR $4^{\Delta \mathrm{IEC}}$ and wild-type mice to $16 \mathrm{~S}$ pyrosequencing followed by UniFrac clustering analysis, ${ }^{19}$ and then performed a detailed analysis of the bacterial meta-transcriptome derived from both mouse strains. The composition of the 20 most abundant operational taxonomic units in wild-type and TLR4 ${ }^{\triangle \mathrm{IEC}}$ mice are shown in Table $\mathbf{1}$ and the taxonomic domains are shown in Figure 4a. At the phyla level, the intestinal microbiota of both TLR4 ${ }^{\Delta \mathrm{IEC}}$ and wild-type mice were dominated by Bacteroidetes, Firmicutes, and Proteobacteria. Although there was an apparent difference in the stool Verrucomicrobia between strains, this was not statistically significant $(P=0.09)$. However, the intestinal microbiota in TLR4 ${ }^{\triangle \mathrm{IEC}}$ mice were revealed to cluster differently from those in wild-type mice (Figure $4 \mathbf{b}$ ), and displayed a significantly lower diversity (Figure 4c). To determine the functional consequences of the loss of TLR4 within the intestinal epithelium on microbial function, we next performed a detailed metatranscriptomic analysis of the stool samples from wild-type and TLR4 ${ }^{\triangle \mathrm{IEC}}$ mice. After removing the sequences from mouse origin and thus confining the analysis to bacterial products, 1,001,228 bacterial sequences were identified from the metatranscriptome which were converted to 4,067 unique clusters of orthologous groups by running against the clusters of orthologous groups protein database. This analysis determined that 246 clusters of orthologous groups were found to be differentially expressed between TLR4 ${ }^{\triangle \mathrm{IEC}}$ and wild-type mice which were then grouped into the KEGG (Kyoto Encyclopedia of Genes and Genomes) pathways. This investigation revealed a significant alteration in several functional categories that may play a role in the development of metabolic syndrome, including the metabolism of lipid, amino acids, and nucleotides (Table 2), in the bacteria from TLR4 ${ }^{\Delta \mathrm{IEC}}$ as compared with wild-type mice, providing insights into the mechanisms by which altered bacterial signaling in response to TLR4 deficiency could lead to the development of metabolic syndrome.

In seeking to investigate the potential mechanisms by which TLR4 expression in the intestinal epithelium could influence the composition of the microbiota in the first place, we observed that mRNA expression of the anti-microbial peptide lysozyme-which has an established role in regulating the composition of the intestinal microbiota and maintaining intestinal homeostasis ${ }^{20}$-was significantly reduced in the small intestine of TLR4 ${ }^{\triangle \mathrm{IEC}}$ mice as compared with wild-type mice (Supplementary Figure 5). In addition, the administration of antibiotics did not restore lysozyme 
expression to wild-type levels (Supplementary Figure 5), suggesting a predominant role for intestinal TLR4 in its regulation. These findings led us to next investigate how TLR4mediated host-microbial interactions could lead to the development of metabolic syndrome in mice.
TLR4 expression within the intestinal epithelium regulates the expression of metabolic and inflammatory genes in mice

To investigate further how TLR4 expression within the intestinal epithelium could lead to the development of a i Body weight, antibiotics

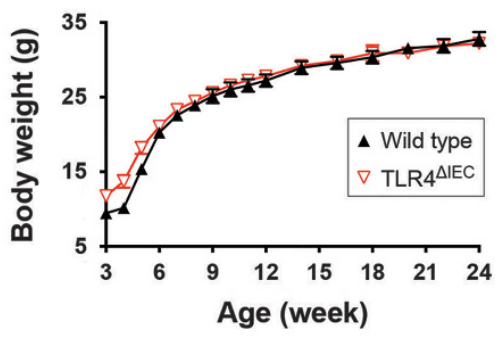

c

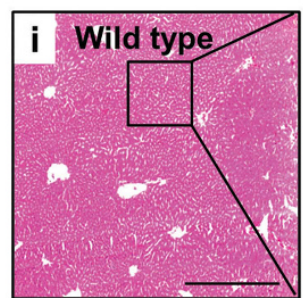

d

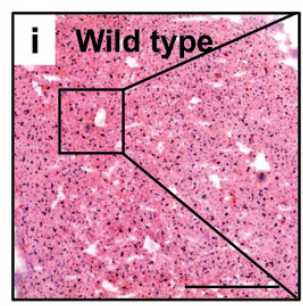

e

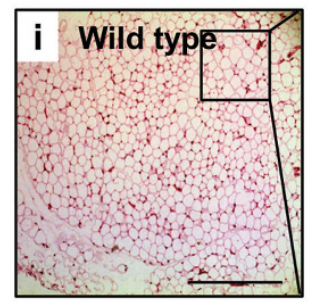

f

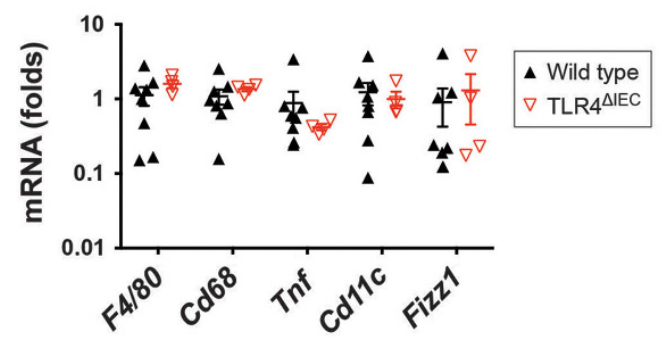

b

Weight of adipose tissues and liver, antibiotics
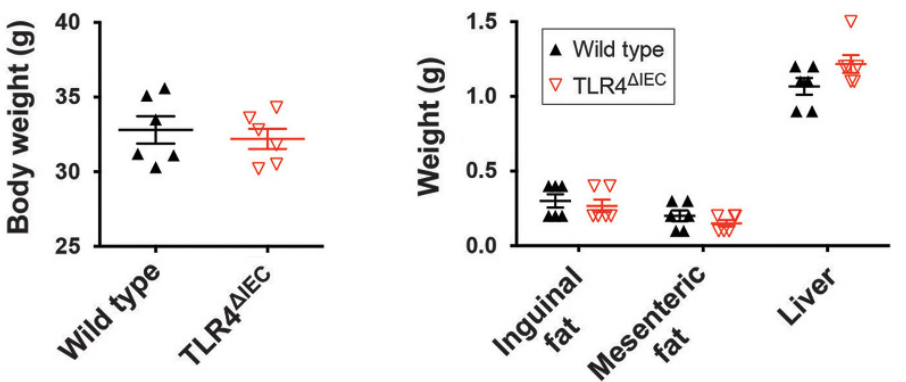

Liver H\&E, antibiotics
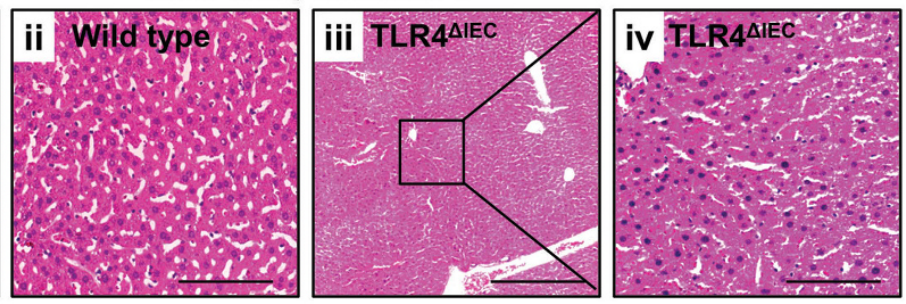

Liver oil red $\mathrm{O}$, antibiotics
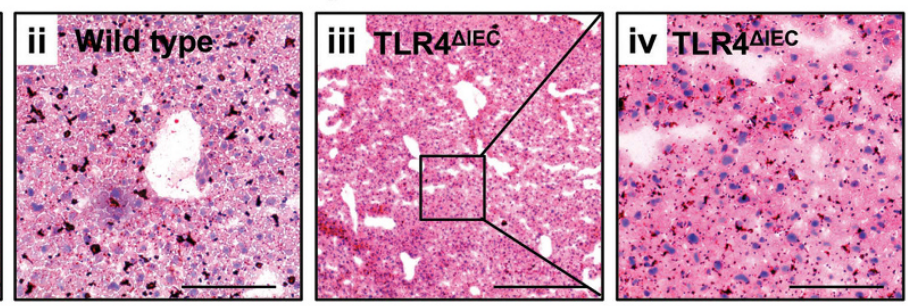

Adipose tissue H\&E, antibiotics
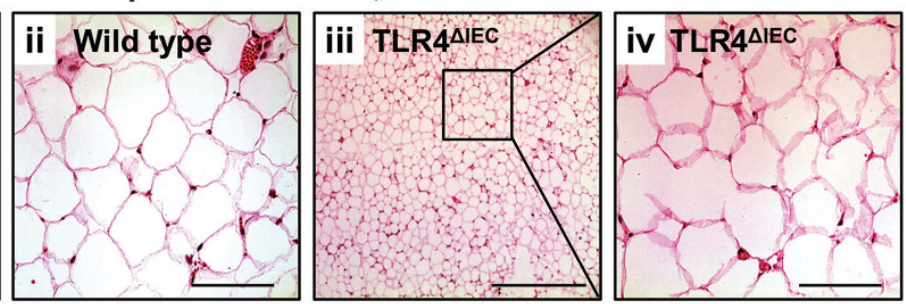

g Glucose tolerance test, antibiotics

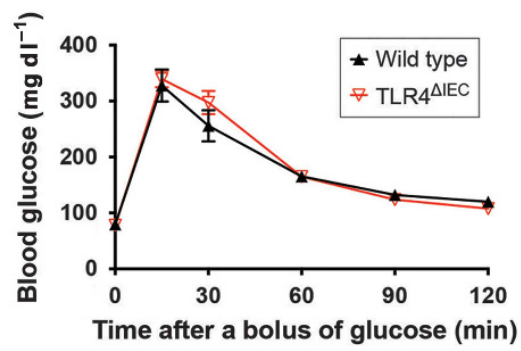


metabolic syndrome, we next performed an unbiased RNA sequencing analysis on intestinal mucosal samples obtained from the terminal ileum of wild-type and TLR4 ${ }^{\triangle \mathrm{IEC}}$ mice. This study revealed that key genes within the metabolically relevant peroxisome proliferator-activated receptor (PPAR) signaling pathway were significantly downregulated in TLR $4^{\Delta \mathrm{IEC}}$ mice compared to wild-type mice (Table 3 and Supplementary Figure 6A), although the PPAR genes themselves were

Table 1 Twenty most abundant OTUs in the stools of wild-type and TLR4 ${ }^{\mathrm{AIEC}}$ mice

\begin{tabular}{|c|c|c|c|c|c|c|c|}
\hline OTU & $\begin{array}{l}\text { Test- } \\
\text { statistic }\end{array}$ & $\boldsymbol{P}$ & FDR P & $\begin{array}{l}\text { Bonferroni } \\
\boldsymbol{P}\end{array}$ & $\begin{array}{l}\mathrm{TLR}^{\Delta \mathrm{IEC}} \\
\text { mean }\end{array}$ & $\begin{array}{l}\text { WT } \\
\text { mean }\end{array}$ & Taxonomy \\
\hline 250270 & 18.356813 & 0.000018 & 0.010953 & 0.042384 & 0.8 & 28.4 & Firmicutes, Clostridia, Clostridiales \\
\hline 214919 & 17.787644 & 0.000025 & 0.010953 & 0.057152 & 0.6 & 18.7 & Firmicutes, Bacilli, Turicibacterales, Turicibacteraceae, Turicibacter \\
\hline 449353 & 17.487012 & 0.000029 & 0.010953 & 0.066939 & 0.5 & 12.2 & $\begin{array}{l}\text { Firmicutes, Clostridia, Clostridiales, Dehalobacteriaceae, } \\
\text { Dehalobacterium }\end{array}$ \\
\hline 296045 & 17.274160 & 0.000032 & 0.010953 & 0.074871 & 47.1 & 0.1 & $\begin{array}{l}\text { Bacteroidetes, Bacteroidia, Bacteroidales, Bacteroidaceae, } \\
\text { Bacteroides }\end{array}$ \\
\hline 193680 & 17.033824 & 0.000037 & 0.010953 & 0.084970 & 0.0 & 6.1 & Firmicutes, Clostridia, Clostridiales, Lachnospiraceae \\
\hline 263518 & 16.988636 & 0.000038 & 0.010953 & 0.087016 & 10.7 & 0.2 & $\begin{array}{l}\text { Proteobacteria, Deltaproteobacteria, Desulfovibrionales, } \\
\text { Desulfovibrionaceae }\end{array}$ \\
\hline 4466511 & 16.979866 & 0.000038 & 0.010953 & 0.087419 & 27.5 & 0.2 & $\begin{array}{l}\text { Bacteroidetes, Bacteroidia, Bacteroidales, Odoribacteraceae, } \\
\text { Odoribacter }\end{array}$ \\
\hline 1105589 & 16.962352 & 0.000038 & 0.010953 & 0.088229 & 75.3 & 0.2 & Bacteroidetes, Bacteroidia, Bacteroidales, S24-7 \\
\hline 262752 & 16.627907 & 0.000045 & 0.010953 & 0.105234 & 2.0 & 241.8 & Bacteroidetes, Bacteroidia, Bacteroidales, S24-7 \\
\hline 312322 & 16.379482 & 0.000052 & 0.010953 & 0.119966 & 2.4 & 56.6 & Bacteroidetes, Bacteroidia, Bacteroidales, S24-7 \\
\hline 2937207 & 16.371329 & 0.000052 & 0.010953 & 0.120483 & 284.5 & 1.1 & $\begin{array}{l}\text { Deferribacteres, Deferribacteres, Deferribacterales, Deferribactera- } \\
\text { ceae, Mucispirillum, schaedleri }\end{array}$ \\
\hline 544996 & 15.889564 & 0.000067 & 0.012439 & 0.155380 & 0.6 & 10.4 & Firmicutes, Clostridia, Clostridiales, Ruminococcaceae, Oscillospira \\
\hline 259820 & 15.775570 & 0.000071 & 0.012439 & 0.165029 & 0.1 & 34.3 & Firmicutes, Clostridia, Clostridiales \\
\hline 176868 & 15.595223 & 0.000078 & 0.012439 & 0.181539 & 8.0 & 0.0 & $\begin{array}{l}\text { Firmicutes, Clostridia, Clostridiales, Dehalobacteriaceae, } \\
\text { Dehalobacterium }\end{array}$ \\
\hline 835900 & 15.543325 & 0.000081 & 0.012439 & 0.186591 & 112.4 & 0.0 & $\begin{array}{l}\text { Bacteroidetes, Bacteroidia, Bacteroidales, Odoribacteraceae, } \\
\text { Odoribacter }\end{array}$ \\
\hline 176952 & 14.922099 & 0.000112 & 0.016204 & 0.259267 & 0.1 & 2.0 & Firmicutes, Clostridia, Clostridiales \\
\hline 259859 & 14.227922 & 0.000162 & 0.021115 & 0.374751 & 1.2 & 32.8 & Bacteroidetes, Bacteroidia, Bacteroidales, S24-7 \\
\hline 186358 & 14.201435 & 0.000164 & 0.021115 & 0.380063 & 3.5 & 0.1 & $\begin{array}{l}\text { Bacteroidetes, Bacteroidia, Bacteroidales, Bacteroidaceae, } \\
\text { Bacteroides }\end{array}$ \\
\hline 175485 & 13.881567 & 0.000195 & 0.023712 & 0.450533 & 3.5 & 0.1 & $\begin{array}{l}\text { Bacteroidetes, Bacteroidia, Bacteroidales, Bacteroidaceae, } \\
\text { Bacteroides }\end{array}$ \\
\hline 4449524 & 13.549172 & 0.000232 & 0.026888 & 0.537759 & 10.6 & 0.0 & Bacteroidetes, Bacteroidia, Bacteroidales, Prevotellaceae, Prevotella \\
\hline
\end{tabular}

Abbreviations: FDR, false discovery rate; OTU, operational taxonomic unit; TLR4, Toll-like receptor 4.

Figure 3 The administration of broad spectrum antibiotics prevented the development of obesity and metabolic syndrome in TLR4 ${ }^{\Delta I E C}$ mice. (a) The body weight of wild-type $(n=6)$ and TLR4 ${ }^{\Delta \mathrm{IEC}}(n=6)$ mice treated with antibiotics from the age of $3-24$ weeks (i) and at the age of 24 weeks (ii). Data are mean \pm s.e.m.; each symbol represents a separate mouse. (b) The weight of the inguinal fat, mesenteric fat, and liver of wild-type $(n=6)$ and TLR4 ${ }^{\Delta I E C}(n=6)$ mice treated with antibiotics at the age of 24. Data are represented as mean \pm s.e.m.; each symbol represents a separate mouse. (c) Representative photomicrographs showing liver sections of wild-type mice (i and ii) and TLR4 ${ }^{\triangle I E C}$ mice (iii and iv) treated with antibiotics at the age of 24 weeks, which were stained with hematoxylin and eosin. Scale bars represent $400 \mu \mathrm{m}$ and $100 \mu \mathrm{m}$ in the $\times 10$ (i and iii) and $\times 40$ (ii and iv) panels, respectively. (d) Representative photomicrographs showing liver sections of wild-type mice (i and ii) and TLR4 ${ }^{\Delta \mathrm{IEC}}$ mice (iii and iv) treated with antibiotics at the age of 24 weeks, which were stained with oil red $\mathrm{O}$. Scale bars represent $400 \mu \mathrm{m}$ and $100 \mu \mathrm{m}$ in the $\times 10$ (i and iii) and $\times 40$ (ii and iv) panels, respectively. (e) Representative photomicrographs showing white adipose tissue sections of wild-type mice (i and ii) and TLR4 ${ }^{\Delta \mathrm{IEC}}$ mice (iii and iv) treated with antibiotics at the age of 24 weeks, which were stained with hematoxylin and eosin. Scale bars represent $400 \mu \mathrm{m}$ and $100 \mu \mathrm{m}$ in the $\times 10$ (i and iii) and $\times 40$ (ii and iv) panels, respectively. (f) qPCR showing the expression of macrophage markers (F4/80 and Cd68), M1 macrophage markers (Tnf and Cd11c), and M2 macrophage marker (Retn/b) in the white adipose tissues of wild-type $(n=6)$ and TLR4 ${ }^{\Delta \mathrm{IEC}}(n=6)$ mice treated with antibiotics at the age of 24 weeks. All data were normalized to the mRNA expression of $R p l p 0$, and the mRNA expression in wild-type mice was set to 1. Data are represented as mean \pm s.e.m.; each symbol represents a separate mouse. (g) The oral glucose tolerance test (OGTT) of wild-type $(n=6)$ and TLR4 ${ }^{\Delta \mathrm{IEC}}(n=6)$ mice treated with antibiotics at the age of 24 weeks is shown. Data are represented as mean \pm s.e.m.; ${ }^{\star} P<0.05$ wild-type vs. TLR4 ${ }^{\Delta \mathrm{IEC}}$ mice. TLR4, Toll-like receptor 4. 


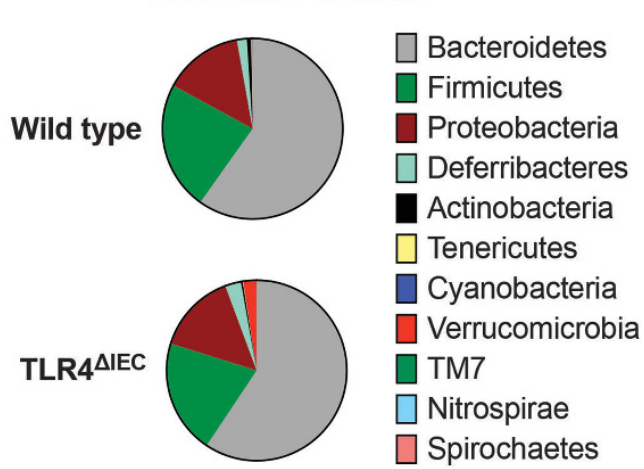

b

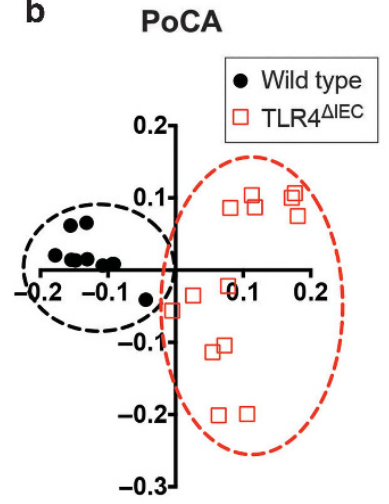

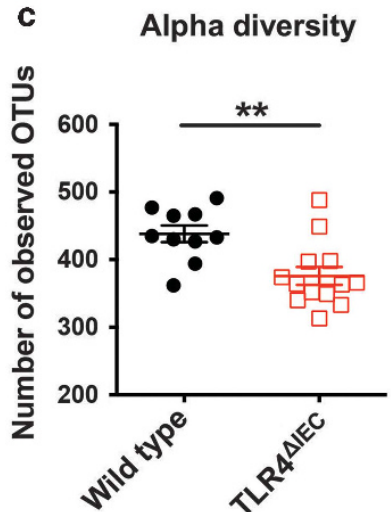

Figure 4 The effects of intestinal epithelial TLR4 on the luminal microbiota in mice. (a) The major taxonomic domains of intestinal microbiota of wild-type and TLR $4{ }^{\Delta \mathrm{IEC}}$ mice fed standard chow at the age of 24 weeks. (b) UNIFRAG clustering analysis of the intestinal microbiota of wild-type $(n=10)$ and $\operatorname{TLR}^{\Delta \mathrm{IEC}}(n=13)$ mice fed standard chow at the age of 24 weeks. (c) The alpha-diversity of the intestinal microbiota of wild-type $(n=10)$ and TLR4 $4^{\Delta \mathrm{EC}}$ $(n=13)$ mice fed standard chow at the age of 24 weeks. Data are represented as mean \pm s.e.m.; ${ }^{*} P<0.05$ between wild-type and TLR4 ${ }^{\Delta \mathrm{IEC}}$ mice; each symbol represents a separate mouse. TLR4, Toll-like receptor 4.

unchanged (Supplementary Figure 6B). Specific PPARregulated genes that were downregulated included fastinginduced adipose factor (Fiaf), fatty acid transport protein 1 (Fatp1), 3-hydroxy-3-methylglutaryl-CoA synthase 2 (Hmgcs2), and fatty acid-binding protein 1 (Fabpl) (Figure 5a). In control experiments, the expression of those PPARregulated genes were similar between wild-type and TLR4 ${ }^{\Delta \text { Myeloid }}$ mice (Supplementary Figure $6 \mathrm{C}$ ), consistent with the lack of metabolic syndrome observed in the TLR4 ${ }^{\Delta \text { Myeloid }}$ mice. Given that we had identified that the administration of antibiotics prevented the development of metabolic syndrome in TLR4 ${ }^{\Delta \mathrm{IEC}}$ mice, we next sought to assess the effects of antibiotic administration of the expression of these key PPAR-regulated genes. As shown in Figure $\mathbf{5 b}$, the administration of broad spectrum antibiotics prevented the previously observed differences in expression of Fiaf, Fatp1, Hmgcs2, and Fabp 1, in both wild-type and TLR4 ${ }^{\triangle \mathrm{IEC}}$ mice after treatment with broad spectrum antibiotics.

We next evaluated whether the reduced expression of these key PPAR-regulated metabolic genes in response to TLR4 deletion was required for the development of metabolic syndrome. To do so, we next administrated pharmacologic agonists of the PPAR signaling pathway to wild-type and TLR4 ${ }^{\triangle I E C}$ mice and assessed the consequences on glucose metabolism. Importantly, the oral administration of bezafibrate (which activates all three PPAR subtypes), rosiglitazone (which selectively activates PPAR gamma), or WY-14643 (which activates PPAR alpha, gamma, and delta) completely reversed the impaired glucose tolerance in TLR4 ${ }^{\triangle \mathrm{IEC}}$ mice (Figure 5c), and restored the expression of these PPAR-regulated genes, namely Fiaf, Fatp1, Hmgcs2, and Fabp1 (Figure 5d). It is noteworthy that TLR4 deletion did not only regulate PPAR-regulated metabolic genes, as the gene expression profile of TLR ${ }^{\Delta \mathrm{IEC}}$ mice revealed a pro-inflammatory phenotype, characterized by upregulated expression of macrophage markers (F4/80, Cd68, and Mcp1, Supplementary Figure 6D), neutrophil markers (Mpo and Elane, Supplementary Figure 6E), a trend towards increased expression of the pro-inflammatory cytokine interleukin 6 (Il6) in the ileum (Supplementary Figure 6F). These findings are consistent with a potential degree of subtle inflammation in the small intestine of TLR $4^{\triangle I E C}$ mice, which could contribute to the development of metabolic syndrome. Taken together, these findings suggest that TLR4 regulates both host and bacterial genes that have a key role in energy metabolism, which acts in concert to govern the development of metabolic syndrome and obesity in mice.

\section{DISCUSSION}

We now show that TLR4 expression in the intestinal epithelium plays a previously unrecognized role in the development of metabolic syndrome in mice through the regulation of hostbacterial interactions. The conclusion that TLR4 deficiency from the intestinal epithelium leads to the development of metabolic syndrome was reached by studying five different strains of mice, including TLR4 ${ }^{\triangle \mathrm{IEC}}$ mice which developed metabolic syndrome, as well as mice lacking TLR4 on myeloid cells, mice globally deficient in TLR4, mice expressing TLR4 only on the intestinal epithelium and wild-type mice which each did not. In terms of understanding how TLR4 signaling in the intestinal epithelial cells regulates body energy metabolism, we now describe a key role for TLR4 in the regulation of the intestinal microbiota, as the administration of antibiotics or co-housing of TLR4 ${ }^{\triangle \mathrm{IEC}}$ mice with wild-type mice reversed the induction of metabolic syndrome. We further showed that TLR4 deletion from the intestinal epithelium led to a downregulation of key genes in the regulation of host metabolism, namely PPAR-regulated genes, and that PPAR activation reversed the development of metabolic syndrome. Taken together, these findings illustrate important roles for TLR4 in the regulation of bacteria-epithelium interactions in the development of metabolic syndrome, and suggest the possibility that modulating either the microbiota or host PPARregulated genes could offer novel preventive therapeutic approaches for this disease. 
Table 2 Altered KEGG metabolic pathways of the intestinal microbiota between wild-type and TLR4 ${ }^{\Delta \mathrm{IEC}}$ mice

\begin{tabular}{|c|c|}
\hline Class of metabolism pathways & Metabolic pathway name \\
\hline \multirow[t]{5}{*}{ Energy metabolism } & Carbon fixation in photosynthetic organisms \\
\hline & Carbon fixation pathways in prokaryotes \\
\hline & Methane metabolism \\
\hline & Nitrogen metabolism \\
\hline & Oxidative phosphorylation \\
\hline \multirow[t]{11}{*}{ Carbohydrate metabolism } & $\begin{array}{l}\text { Amino sugar and nucleotide } \\
\text { sugar metabolism }\end{array}$ \\
\hline & Butanoate metabolism \\
\hline & C5-Branched dibasic acid metabolism \\
\hline & Citrate cycle (TCA cycle) \\
\hline & Glycolysis/Gluconeogenesis \\
\hline & Glyoxylate and dicarboxylate metabolism \\
\hline & Inositol phosphate metabolism \\
\hline & Pentose phosphate pathway \\
\hline & Propanoate metabolism \\
\hline & Pyruvate metabolism \\
\hline & Starch and sucrose metabolism \\
\hline \multirow[t]{2}{*}{ Lipid metabolism } & Ether lipid metabolism \\
\hline & Glycerophospholipid metabolism \\
\hline \multirow[t]{5}{*}{ Amino acid metabolism } & $\begin{array}{l}\text { Alanine, aspartate and glutamate } \\
\text { metabolism }\end{array}$ \\
\hline & Arginine and proline metabolism \\
\hline & Histidine metabolism \\
\hline & Lysine biosynthesis \\
\hline & Valine, leucine and isoleucine biosynthesis \\
\hline \multirow{4}{*}{$\begin{array}{l}\text { Metabolism of other } \\
\text { amino acids }\end{array}$} & Cyanoamino acid metabolism \\
\hline & D-Glutamine and D-glutamate metabolism \\
\hline & Glutathione metabolism \\
\hline & Phosphonate and phosphinate metabolism \\
\hline \multirow[t]{3}{*}{ Amino acid metabolism } & Valine, leucine and isoleucine degradation \\
\hline & Purine metabolism \\
\hline & Pyrimidine metabolism \\
\hline \multirow{5}{*}{$\begin{array}{l}\text { Metabolism of cofactors } \\
\text { and vitamins }\end{array}$} & Biotin metabolism \\
\hline & Nicotinate and nicotinamide metabolism \\
\hline & Pantothenate and CoA biosynthesis \\
\hline & Porphyrin and chlorophyll metabolism \\
\hline & $\begin{array}{l}\text { Ubiquinone and other } \\
\text { terpenoid-quinone biosynthesis }\end{array}$ \\
\hline \multirow{6}{*}{$\begin{array}{l}\text { Xenobiotics biodegradation } \\
\text { and metabolism }\end{array}$} & Benzoate degradation \\
\hline & $\begin{array}{l}\text { Chlorocyclohexane and } \\
\text { chlorobenzene degradation }\end{array}$ \\
\hline & Fluorobenzoate degradation \\
\hline & Nitrotoluene degradation \\
\hline & $\begin{array}{l}\text { Polycyclic aromatic hydrocarbon } \\
\text { degradation }\end{array}$ \\
\hline & Toluene degradation \\
\hline $\begin{array}{l}\text { Biosynthesis of other } \\
\text { secondary metabolites }\end{array}$ & Penicillin and cephalosporin biosynthesis \\
\hline $\begin{array}{l}\text { Glycan biosynthesis } \\
\text { and metabolism }\end{array}$ & $\begin{array}{l}\text { Glycosylphosphatidylinositol(GPI)- } \\
\text { anchor biosynthesis }\end{array}$ \\
\hline
\end{tabular}

Abbreviations: KEGG, Kyoto Encyclopedia of Genes and Genomes; PPAR, peroxisome proliferator-activated receptor.
Table 3 Pathways significantly altered in ileum of wild-type and TLR4 ${ }^{\mathrm{IIEC}}$ mice

\begin{tabular}{ll}
\hline Pathway name & $P$-value \\
\hline WebGestalt analysis & \\
DNA replication & 0.0087 \\
PPAR signaling pathway & 0.0087 \\
Fructose and mannose metabolism & 0.0391 \\
Vitamin digestion and absorption & 0.0391 \\
& \\
Pathway Express analysis & \\
Circadian rhythm & 0.00008 \\
DNA replication & 0.00081 \\
PPAR signaling pathway & 0.00156 \\
Base excision repair & 0.02190 \\
Ingenuity Pathway analysis & \\
Cell cycle control of chromosomal replication & \\
LPS/IL-1 mediated inhibition of RXR function & 0.00004 \\
Retinol biosynthesis & 0.00417 \\
Antigen presentation pathway & 0.00912 \\
Bupropion degradation & 0.01202 \\
Estrogen biosynthesis & 0.02042 \\
Glutathione-mediated detoxification & 0.02399 \\
PPAR $\alpha$ /RXR $\alpha$ activation & 0.02399 \\
Acetone degradation I (to Methylglyoxal) & 0.02692 \\
Renal cell carcinoma signaling & 0.02692 \\
Adenosine nucleotides degradation II & 0.03090 \\
Glucocorticoid biosynthesis & 0.03981 \\
Mineralocorticoid biosynthesis & \\
Abbreviation: PPAR, peroxisome proliferator-activated receptor. & \\
\hline & \\
Maturity Onset Diabetes of Young (MODY) signaling & \\
\hline
\end{tabular}

The current study adds to a body of work that has examined the roles of TLR4 in the pathogenesis of metabolic syndrome, around which there has been significant controversy. Researchers have determined that TLR4 inhibition either reduced, ${ }^{14,21,22}$ increased ${ }^{16}$, or had no effect ${ }^{15}$ on diet-induced obesity in mice, and attributed these opposing findings to differences in food consumption, ${ }^{16}$ or energy expenditure ${ }^{22}$ between the knockout and wild-type animals. We now report that the lack of TLR4 on the intestinal epithelium as opposed to other cell types is responsible for the development of metabolic syndrome, and that TLR4-dependent differences in the genetic pathways that drive host metabolism play an important mechanistic role. The cell-specific effect of TLR4 on host metabolism in the current study is supported by earlier findings showing that deleting TLR4 from hepatic cells improved insulin resistance, ${ }^{23}$ while deleting TLR4 from myeloid cells either improved ${ }^{21}$ or had no 
a
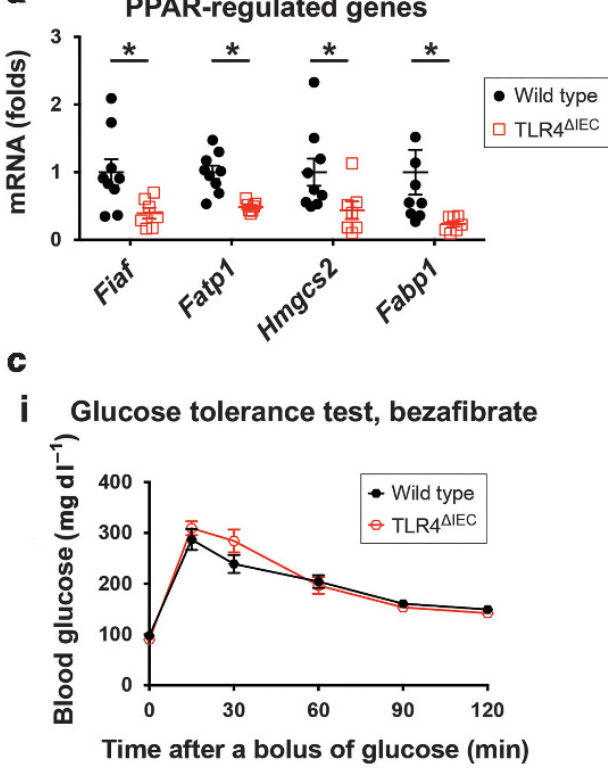

ii Glucose tolerance test, rosiglitazone

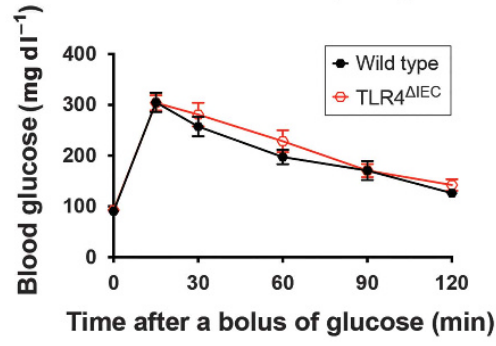

iii Glucose tolerance test, WY-14643

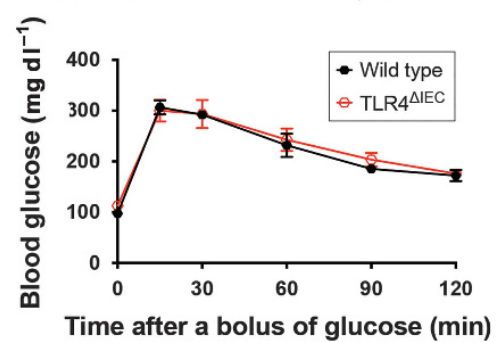

b PPAR-regulated genes, antibiotics

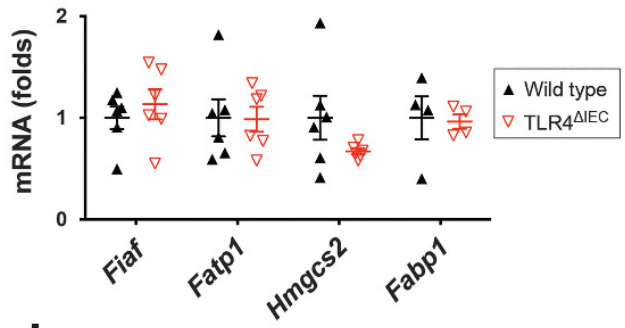

d

i PPAR-regulated genes, bezafibrate

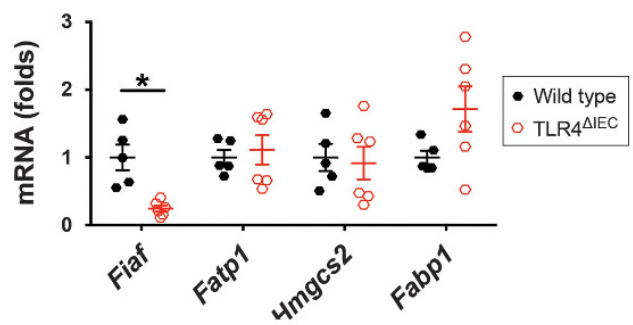

ii PPAR-regulated genes, rosiglitazone

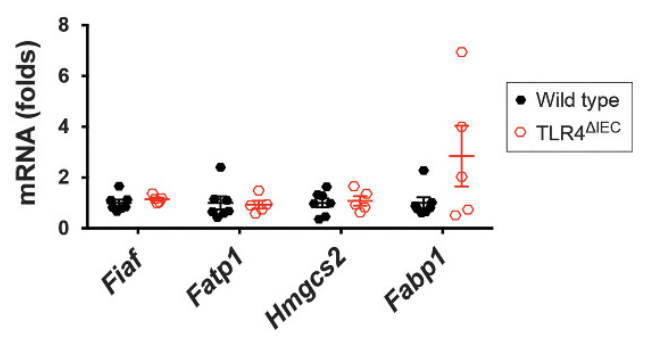

iii PPAR-regulated genes, WY-14643

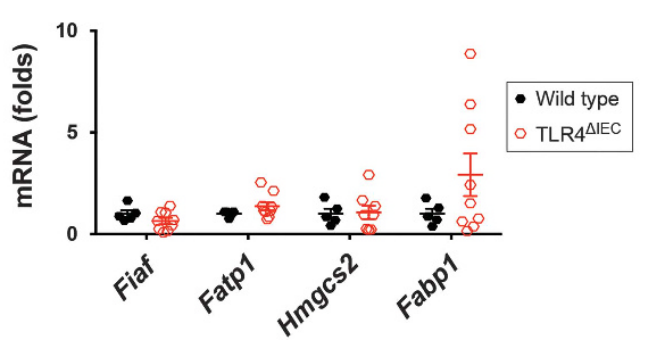

Figure 5 Intestinal epithelial TLR4 regulates the expression of PPAR-related genes in the gut while PPAR agonists reversed the glucose intolerance in TLR4 ${ }^{\Delta I E C}$ mice. (a,b): qPCR showing the expression of PPAR family genes Fiaf, Fatp1, Hmgcs2 and Fabp1 in the ileum of wild-type ( $n=9$ and 6 , respectively) and TLR $4^{\Delta \mathrm{IEC}}(n=7$ and 6 , respectively) mice fed standard chow at the age of 24 weeks in the absence (a) or presence (b) of oral antibiotics. All data were normalized to the mRNA expression of Rplp0, and the mRNA expression in wild-type mice was set to 1. Data are represented as mean \pm s.e.m.; ${ }^{*} P<0.05$ wild-type vs. TLR4 ${ }^{\Delta \mathrm{EC}}$ mice; each symbol represents a separate mouse. (c) Blood glucose concentrations during oral glucose tolerance test of wild-type $\left(n=5,7\right.$, and 5, respectively) and TLR4 ${ }^{\Delta I E C}(n=6,6$, and 9, respectively) mice treated with PPAR agonists bezafibrate (i), rosiglitazone (ii), and WY-14643 (iii) at the age of 24 weeks are shown. Data are represented as mean \pm s.e.m., ${ }^{*} P<0.05$ wild-type vs. TLR4 ${ }^{\Delta I E C}$ mice. (d) qPCR showing mRNA expression of Fiaf, Fatp1, Hmgcs2 and Fabp1 in the ileum of wild-type $\left(n=5,7\right.$, and 5 , respectively) and TLR ${ }^{\Delta I E C}$ ( $n=6,5$, and 9 , respectively) mice treatment with PPAR agonists bezafibrate (i), rosiglitazone (ii), and WY-14643 (iii) at the age of 24 weeks were analyzed using qPCR. All data were normalized to the mRNA expression of Rplp0, and the mRNA expression in wild-type mice was set to 1. Data are represented as mean \pm s.e.m.; each symbol represents a separate mouse. ${ }^{\star} P<0.05$ wild-type vs. TLR4 ${ }^{\Delta I E C}$ mice. TLR4, Toll-like receptor 4 ; PPAR, peroxisome proliferator-activated receptor; qPCR, quantitative PCR.

effect on insulin resistance. ${ }^{23}$. It is reassuring to us that the impaired glucose tolerance in the TLR4 $4^{\mathrm{AIEC}}$ mice was consistently observed over a 4 -year period, and was seen in two different animal colonies at two separate institutions, namely at the University of Pittsburgh and Johns Hopkins University.

One of the most intriguing findings of the current work is the observation that the expression of TLR4 on the intestinal 
epithelium plays a key role not only in the composition but also in the meta-transcriptomic profile of the intestinal microbiota. Explaining, rather than speculating, the role of specific microbial groups would require a more focused investigation, including work with gnotobiotic mice with defined gut microbial communities. The meta-transcriptome analysis of the bacteria in wild-type and TLR4 ${ }^{\triangle \mathrm{IEC}}$ mice intestines identified key differences which were primarily linked to carbohydrate metabolism (11 pathways) and energy metabolism (5 pathways) between strains. The observed changes in the microbiota gene expression in the TLR4 ${ }^{\triangle \mathrm{IEC}}$ mice may have effects on host metabolism, as suggested by prior investigators. Specifically, Musso et al. have shown that changes in gene expression in gut microbiota metabolism may lead to increased nutrient absorption and bile acid reabsorption leading to metabolic syndrome, ${ }^{24}$ and this topic has been reviewed in recent years. ${ }^{25-28}$ Given that the mammalian intestine has a limited ability to hydrolyze complex polysaccharides, it is noteworthy that we found that 11 genes for carbohydrate metabolism pathways were altered in the microbiota of the TLR4 ${ }^{\triangle I E C}$ mice which developed metabolic syndrome. These findings are reminiscent of the observations of prior studies showing that the abundance of Firmicutes vs. Bacteroidetes has been linked to the development of obesity ${ }^{7}$ through the differential ability of these strains to break down complex carbohydrates, and thus vary the degree of carbohydrate delivery and absorption by the host. ${ }^{29}$

While the current findings reveal that TLR4 expression in the intestinal epithelium can impact the composition of the intestinal microbiota, a precise explanation of how this occurs remains lacking. We have previously shown that the deletion of intestinal epithelial TLR4 leads to increased expression of mucin MUC2 ${ }^{30}$ which is secreted by goblet cells and forms a mucus barrier which can influence the growth and composition of commensal bacteria in the small intestine. ${ }^{31}$ Further, we now demonstrate that TLR $4^{\Delta \mathrm{IEC}}$ mice reveal significantly reduced expression of the antimicrobial peptide lysozyme (Supplementary Figure 5), which is secreted by Paneth cells and plays important roles in maintaining the composition of the intestinal microbiota. ${ }^{32}$ It is possible that the host expression of TLR4 could alter the composition of the microbiota through either effects on goblet cells or lysozyme secretion, and do so in a manner that influences metabolic genes, for reasons that are not obvious. Of note, $\mathrm{TRIF}^{-1-}$ mice were shown to also exhibit increased global cells, ${ }^{30}$ reduced lysozyme-positive Paneth cells, ${ }^{33}$ and more interestingly, impaired glucose tolerance ${ }^{34}$, supporting this concept, and indicating a potential role for TLR4-TRIF signaling in the development of metabolic syndrome in TLR4 ${ }^{\triangle \mathrm{IEC}}$ mice.

A major finding of the current study centered around the observation that TLR4 expression within the terminal ileum plays a previously unrecognized role in the regulation of key metabolic and inflammatory genes within the intestine of the host, in particular those within the PPAR family. ${ }^{35,36}$ It is noteworthy that in inflammatory diseases, PPAR signaling can decrease the extent of TLR4 signaling in myeloid cells, ${ }^{37,38}$ adipocytes, ${ }^{39}$ and the intestinal epithelium, ${ }^{40}$ linking the PPAR signaling with altered TLR4 responsiveness. We now extend these prior findings by showing that the reverse can also occur, namely that TLR4 deficiency also reduces PPAR expression. Prior authors have shown that high-fat-diet-induced obesity is related to an increase in circulating free fatty acids, which can act as endogenous ligands of TLR ${ }^{41}$ and $\mathrm{PPAR}^{42}$ thus providing a potential explanation as to why TLR4-mutant mice may be protected from obesity and metabolic syndrome. ${ }^{41}$ However, in the current study, in which we show that TLR4 ${ }^{\Delta \mathrm{IEC}}$ mice are at greater risk for metabolic syndrome and obesity, we now posit that in the presence of a non-high-fat diet, in which circulating free fatty acids are not expected to be increased, the genetic consequences of intestinal epithelial TLR4 deficiency predominate, namely a lack of PPAR, which can negatively regulate metabolism in mice. ${ }^{43},{ }^{44}$ In support of this concept, agonists of PPAR profoundly reversed the effects of TLR4 deficiency on the development of metabolic syndrome in the TLR4 ${ }^{\Delta \mathrm{IEC}}$ mice (Figure 5c).

It is noteworthy that the current findings may allow us to postulate a general signaling mechanism by which bacterial recognition by microbial receptors in the intestinal epithelium leads to alterations in the metabolic profile of the host. Specifically, the work of Gewirtz has revealed that mice lacking the receptor for certain Gram-negative species including Salmonella, namely Toll-like receptor 5, either globally $\left(\mathrm{TLR}^{-1-}\right)^{5}$ or in the intestinal epithelium $\left(\mathrm{TLR} 5^{\mathrm{AIEC}}\right),{ }^{45}$ or mice lacking the conserved TLR adaptor proteins namely MyD88 (MyD88 $\left.{ }^{-1-}\right)^{46}$ or TRIF (TRIF $\left.{ }^{-1-}\right){ }^{34}$ each develop both low-grade intestinal inflammation and metabolic syndrome, supporting the concept that bacterial signaling influences metabolism in the host through MyD88 and/or TRIF. Further studies revealed that mice lacking TLR5 from dendritic cells $\left(\mathrm{TLR}^{\triangle \mathrm{DC}}{ }^{45}{ }^{45}\right.$ or mice lacking MyD88 from dendritic cells $\left(\mathrm{MyD} 88^{\Delta \mathrm{DC}}\right)^{47}$ or other myeloid cells

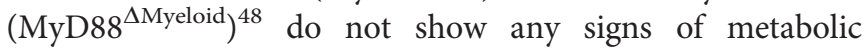
syndrome. By contrast, additional studies reveal that the deletion of MyD88 from myeloid cells $\left(\mathrm{MyD} 88^{\Delta \text { Myeloid }}\right.$ ) or endothelial cells $\left(\mathrm{MyD} 88^{\Delta \mathrm{Endo}}\right)$ protected mice from high-fatdiet-induced metabolic syndrome. ${ }^{49}$ These intriguing studies provide further evidence for the cell-specific nature of TLR signaling in the development of metabolic syndrome, as we now reveal to be the case for TLR4.

In summary, we have now shown that TLR4 signaling in the intestinal epithelium plays a key role in the regulation of metabolic syndrome through the regulation of microbial and host metabolic pathways, and that these effects can be reversed by the administration of PPAR agonists. Our findings suggest a novel link between host metabolism, host genetics, and the intestinal microbiota, and indicate that by exploring this relationship in greater detail, we can potentially reverse this complex and highly morbid disease.

\section{METHODS}

Animal strains and experimentation. All mice experiments were approved by the Animal Care and Use Committee of the University of 
Table 4 PCR primers

\begin{tabular}{|c|c|c|}
\hline Gene & Forward primer $\left(5^{\prime}-3^{\prime}\right)$ & Reverse primer $\left(5^{\prime}-3^{\prime}\right)$ \\
\hline$F 4 / 80$ & GCTCCTGGGTGCTGGGCATT & TCCCGTACCTGACGGTTGAGCA \\
\hline 116 & ССААТTСССААТGСТСТССТ & ACCACAGTGAGGAATGTCCA \\
\hline Tnf & САTСТTСTCAAAАTTCGAGTGACAA & TGGGAGTAGACAAGGTACAACCC \\
\hline Retnlb & CGTGGAGAATAAGGTCAAGGAAC & CACACCCAGTAGCAGTCATC \\
\hline Fiaf & СTCCGTGGGGACCTTAACTG & AGAGGATAGTAGCGGCCCTा \\
\hline Fatp1 & GTGCCACCAACAAGAAGATTG & CTGCGGTCACGGAAATACA \\
\hline Hmgcs2 & CAAGCTGGAAACAACCAGCC & TCAACCGAGCCAGGGATITC \\
\hline Fabp1 & GGAAGGACATCAAGGGGGTG & TCACCTTCCAGCTTGACGAC \\
\hline Ppara & AAGAACCTGAGGAAGCCGTTCTGTG & GCAGCCACAAACAGGGAAATGTCA \\
\hline Pparg & AAGAACCATCCGATTGAAGC & CCAACAGCTTCTCCTTCTCG \\
\hline Lysozyme & AAGCTGGCTGACTGGGTGTGTIA & CACTGCAATTGATCCCACAGGCAT \\
\hline LysM & GCAAAACCCCAAGAGCTGTG & CGGTIITGACAGTGTGCTCG \\
\hline
\end{tabular}

Pittsburgh and by the Johns Hopkins University Animal Care and Use Committee. Mice harboring floxed alleles of TLR4 (wild-type), mice in which TLR4 was selectively deleted from the intestinal epithelium $\left(\mathrm{TLR} 4^{\triangle \mathrm{IEC}}\right.$ ), mice that are globally TLR4 deficient $\left(\mathrm{TLR} 4^{-I^{-}}\right.$), and mice in which TLR4 was expressed only in the intestinal epithelium (TLR ${ }^{\mathrm{IEC}-{ }^{-o n l y}}$ ) were generated in our laboratory as recently described. ${ }^{30,50}$ The breeding scheme for the generation of mice in which TLR4 was selectively deleted from the myeloid cells (TLR4 ${ }^{\Delta \text { Myeloid }}$ ), and confirmation of the lack of TLR4 in the macrophages, are shown in Supplementary Methods and Supplementary Figure 7.

All animals were housed in a specific pathogen-free environment on a 12-h-light/12-h-dark cycle with free access to acidified tap water and standard rodent chow (PicoLab mouse diet 20, 22\% kcal\% fat) from weaning until 24 weeks. Only male mice were included for analysis, and up to five male littermates of each strain were housed in one cage after weaning. For co-housing experiments, up to total five male mice of mixed TLR $4^{\triangle \mathrm{IEC}}$ mice and wild-type mice were housed in one cage after weaning. Where indicated, mice were administered a high-fat diet in which $60 \%$ of the total calories were derived from fat. ${ }^{51}$ In further experiments, mice were administered broad spectrum antibiotics in the drinking water $\left(1 \mathrm{gl}^{-1}\right.$ neomycin, $0.5 \mathrm{gl}^{-1}$ vancomycin, $1 \mathrm{gl}^{-1}$ ampicillin and $1 \mathrm{gl}^{-1}$ metronidazole) as the only source of water from the age of 3-24 weeks. PPAR agonist-treated mice received $285 \mathrm{mg} \mathrm{kg}^{-1} \mathrm{day}^{-1}$ bezafibrate, $25 \mathrm{mg} \mathrm{kg}^{-1}$ day $^{-1}$ rosiglitazone, or $140 \mathrm{mg} \mathrm{kg}^{-1}$ day $^{-1} \mathrm{WY}-14643$ orally from the age of 23-24 weeks.

The total abdominal fat content was determined by micro-MRI, in which isoflurane anesthetized mice were secured to a micro-MRI cradle and advanced into the magnet of a 7-T micro-MRI system (Bruker Bio Spin Corporation, Billerica, MA). A rapid acquisition with relaxation enhancement with fat saturation T1 protocol was applied on the abdomen. ${ }^{52}$

Histologic preparation and oil red $\mathbf{O}$ staining. Adipose tissue and liver were freshly harvested, paraformaldehyde-fixed, and embedded in paraffin. Histological staining was carried out on 4 - $\mu$ m-thick sections which were stained with hematoxylin and eosin. Oil red $\mathrm{O}$ staining was performed in fresh liver cryosections which were fixed with $4 \%(\mathrm{w} / \mathrm{v})$ paraformaldehyde, and after washing with $60 \%$ isopropanol, the cryosections were counterstained with hematoxylin.

RNA isolation, cDNA synthesis, and quantitative PCR (qPCR). Total RNA was isolated from the epididymal white adipose tissue and ileum of mice of 24-week-old mice using the RNeasy mini kit (Qiagen, Valencia, CA) following the manufacturer's protocol. Complementary DNA was synthesized from $0.5 \mu \mathrm{g}$ RNA using M-MLV reverse transcriptase. The qPCR analysis was performed with the Bio-Rad CFX96 Real-Time System (Biorad, Hercules, CA) using the primers listed in Table 4. The relative mRNA expression levels were normalized against the expression of housekeeping gene ribosomal protein lateral stalk subunit P0 $(R p l p 0)$ relative to wild-type mice.

Oral glucose tolerance test. Glucose levels were determined via glucometer (Bayer, Whippany, NJ). Oral glucose tolerance test was performed in overnight-fasted 24 -week-old mice administered $2 \mathrm{~g}$ of glucose per kg body weight by oral gavage, and the blood glucose levels were measured via tail puncture at $1 \mathrm{~min}$ before and $15,30,60,90$, and $120 \mathrm{~min}$ after the oral gavage ${ }^{53}$.

Statistical analysis. Data were analyzed for statistical significance by Mann-Whitney test using GraphPad Prism (GraphPad, La Jolla, CA). A $P$-value of less than 0.05 was considered statistically significant, and data are presented as mean \pm s.e.m. as indicated.

SUPPLEMENTARY MATERIAL is linked to the online version of the paper at http://www.nature.com/mi

\section{ACKNOWLEDGMENTS}

DJH is supported by R01GM078238 and R01DK083752 from the National Institutes of Health.

\section{AUTHOR CONTRIBUTIONS}

Conceptualization, PL, CPS, and DJH; Methodology, PL, CPS, and DJH; Investigation, PL, CPS, YY, HJ, TPJ, WBF, AV, KJB, MJM; Writing-Original 
Draft, PL; Writing-Review and Editing, PL, CPS and DJH; Funding acquisition, DJH; Resources, DJH; Supervision, DJH.

\section{DISCLOSURE}

The authors declared no conflict of interest.

(c) 2018 Society for Mucosal Immunology

\section{REFERENCES}

1. Alberti, KG, Zimmet, P \& Shaw, J. Metabolic syndrome - a new worldwide definition. A Consensus Statement from the International Diabetes Federation. Diabet. Med. 23, 469-480 (2006).

2. Brown, AE \& Walker, M. Genetics of insulin resistance and the metabolic syndrome. Curr. Cardiol. Rep. 18, 75 (2016).

3. Kovatcheva-Datchary, P \& Arora, T. Nutrition, the gut microbiome and the metabolic syndrome. Best Pract. Res. Clin. Gastroenterol. 27, 59-72 (2013).

4. Parekh, PJ, Balart, LA \& Johnson, DA. The influence of the gut microbiome on obesity, metabolic syndrome and gastrointestinal disease. Clin. Transl. Gastroenterol. 6, e91 (2015).

5. Vijay-Kumar, $\mathrm{M}$ et al. Metabolic syndrome and altered gut microbiota in mice lacking Toll-like receptor 5. Science 328, 228-231 (2010).

6. Di Luccia, B et al. Rescue of fructose-induced metabolic syndrome by antibiotics or faecal transplantation in a rat model of obesity. PLOS ONE 10, e0134893 (2015).

7. Ley, RE, Turnbaugh, PJ, Klein, S \& Gordon, Jl. Microbial ecology: human gut microbes associated with obesity. Nature 444, 1022-1023 (2006).

8. Ridaura, VK et al. Gut microbiota from twins discordant for obesity modulate metabolism in mice. Science 341, 1241214 (2013).

9. Steinhardt, AP et al. A functional nonsynonymous toll-like receptor 4 gene polymorphism is associated with metabolic syndrome, surrogates of insulin resistance, and syndromes of lipid accumulation. Metabolism 59, 711-717 (2010).

10. Jialal, I, Huet, BA, Kaur, H, Chien, A \& Devaraj, S. Increased toll-like receptor activity in patients with metabolic syndrome. Diabetes Care 35, 900-904 (2012).

11. Hardy, OT, Kim, A, Ciccarelli, C, Hayman, LL \& Wiecha, J. Increased Tolllike receptor (TLR) $m R N A$ expression in monocytes is a feature of metabolic syndrome in adolescents. Pediatr. Obes. 8, e19-e23 (2013).

12. Gay, NJ, Symmons, MF, Gangloff, M \& Bryant, CE. Assembly and Iocalization of Toll-like receptor signalling complexes. Nat. Rev. Immunol. 14, 546-558 (2014).

13. O'Neill, LA, Golenbock, D \& Bowie, AG. The history of Toll-like receptors redefining innate immunity. Nat. Rev. Immunol. 13, 453-460 (2013).

14. Pierre, N, Deldicque, L, Barbe, C, Naslain, D, Cani, PD \& Francaux, M. Tolllike receptor 4 knockout mice are protected against endoplasmic reticulum stress induced by a high-fat diet. PLOS ONE 8, e65061 (2013).

15. Kim, $\mathrm{F}$ et al. Toll-like receptor- 4 mediates vascular inflammation and insulin resistance in diet-induced obesity. Circ. Res. 100, 1589-1596 (2007).

16. Shi, H, Kokoeva, MV, Inouye, K, Tzameli, I, Yin, H \& Flier, JS. TLR4 links innate immunity and fatty acid-induced insulin resistance. J. Clin. Invest. 116, 3015-3025 (2006).

17. Kanwar, P \& Kowdley, KV. The metabolic syndrome and its influence on nonalcoholic steatohepatitis. Clin. Liver Dis. 20, 225-243 (2016).

18. Fujisaka, $\mathrm{S}$ et al. Regulatory mechanisms for adipose tissue M1 and M2 macrophages in diet-induced obese mice. Diabetes 58, 2574-2582 (2009).

19. Lozupone, C \& Knight, R. UniFrac: a new phylogenetic method for comparing microbial communities. Appl. Environ. Microbiol. 71, 82288235 (2005).

20. Bevins, CL \& Salzman, NH. Paneth cells, antimicrobial peptides and maintenance of intestinal homeostasis. Nat. Rev. Microbiol. 9, 356-368 (2011).

21. Saberi, M et al. Hematopoietic cell-specific deletion of toll-like receptor 4 ameliorates hepatic and adipose tissue insulin resistance in high-fat-fed mice. Cell Metab. 10, 419-429 (2009).

22. Tsukumo, DM et al. Loss-of-function mutation in Toll-like receptor 4 prevents diet-induced obesity and insulin resistance. Diabetes $56,1986-$ 1998 (2007).
23. Jia, L et al. Hepatocyte Toll-like receptor 4 regulates obesityinduced inflammation and insulin resistance. Nat. Commun. 5, 3878 (2014).

24. Musso, G, Gambino, R \& Cassader, M. Interactions between gut microbiota and host metabolism predisposing to obesity and diabetes. Annu. Rev. Med. 62, 361-380 (2011).

25. Tremaroli, V \& Backhed, F. Functional interactions between the gut microbiota and host metabolism. Nature 489, 242-249 (2012).

26. Sonnenburg, JL \& Backhed, F. Diet-microbiota interactions as moderators of human metabolism. Nature 535, 56-64 (2016).

27. Nicholson, JK et al. Host-gut microbiota metabolic interactions. Science 336, 1262-1267 (2012).

28. Hooper, LV. Bacterial contributions to mammalian gut development. Trends Microbiol. 12, 129-134 (2004).

29. Li, M et al. Gut carbohydrate metabolism instead of fat metabolism regulated by gut microbes mediates high-fat diet-induced obesity. Benef. Microbes 5, 335-344 (2014).

30. Sodhi, CP et al. Intestinal epithelial Toll-like receptor 4 regulates goblet cell development and is required for necrotizing enterocolitis in mice. Gastroenterology 143, 708-718 e701-705 (2012).

31. Johansson, ME et al. Composition and functional role of the mucus layers in the intestine. Cell. Mol. Life Sci. 68, 3635-3641 (2011).

32. Wittkopf, Netal. Lack of intestinal epithelial atg7 affects paneth cell granule formation but does not compromise immune homeostasis in the gut. Clin. Dev. Immunol. 2012, 278059 (2012).

33. Stockinger, $\mathrm{S}$ et al. TRIF signaling drives homeostatic intestinal epithelial antimicrobial peptide expression. J. Immunol. 193, 42234234 (2014).

34. Hutton, MJ, Soukhatcheva, G, Johnson, JD \& Verchere, CB. Role of the TLR signaling molecule TRIF in beta-cell function and glucose homeostasis. Islets 2, 104-111 (2010).

35. Pineda Torra, I, Gervois, P \& Staels, B. Peroxisome proliferator-activated receptor alpha in metabolic disease, inflammation, atherosclerosis and aging. Curr. Opin. Lipidol. 10, 151-159 (1999).

36. Evans, RM, Barish, GD \& Wang, YX. PPARs and the complex journey to obesity. Nat. Med. 10, 355-361 (2004).

37. Dasu, MR, Park, S, Devaraj, S \& Jialal, I. Pioglitazone inhibits Toll-like receptor expression and activity in human monocytes and $\mathrm{db} / \mathrm{db}$ mice. Endocrinology 150, 3457-3464 (2009).

38. Appel, S, Mirakaj, V, Bringmann, A, Weck, MM, Grunebach, F\& Brossart, P. PPAR-gamma agonists inhibit toll-like receptor-mediated activation of dendritic cells via the MAP kinase and NF-kappaB pathways. Blood 106, 3888-3894 (2005).

39. Rodriguez-Calvo, R et al. Activation of peroxisome proliferator-activated receptor beta/delta inhibits lipopolysaccharide-induced cytokine production in adipocytes by lowering nuclear factor-kappaB activity via extracellular signal-related kinase 1/2. Diabetes 57, 2149-2157 (2008).

40. Eun, CS et al. Attenuation of colonic inflammation by PPARgamma in intestinal epithelial cells: effect on Toll-like receptor pathway. Dig. Dis. Sci. 51, 693-697 (2006).

41. Cani, PD et al. Metabolic endotoxemia initiates obesity and insulin resistance. Diabetes 56, 1761-1772 (2007).

42. Kliewer, SA et al. Fatty acids and eicosanoids regulate gene expression through direct interactions with peroxisome proliferator-activated receptors alpha and gamma. Proc. Natl. Acad. Sci. USA 94, 43184323 (1997).

43. Costet, P, Legendre, C, More, J, Edgar, A, Galtier, P \& Pineau, T. Peroxisome proliferator-activated receptor alpha-isoform deficiency leads to progressive dyslipidemia with sexually dimorphic obesity and steatosis. J. Biol. Chem. 273, 29577-29585 (1998).

44. Chen, $X$ et al. Improvement of dyslipidemia, insulin sensitivity, and energy balance by a peroxisome proliferator-activated receptor alpha agonist. Metab. Clin. Exp. 57, 1516-1525 (2008).

45. Chassaing, B, Ley, RE \& Gewirtz, AT. Intestinal epithelial cell toll-like receptor 5 regulates the intestinal microbiota to prevent low-grade inflammation and metabolic syndrome in mice. Gastroenterology 147, 1363-1377 e1317 (2014).

46. Hosoi, T, Yokoyama, S, Matsuo, S, Akira, S \& Ozawa, K. Myeloid differentiation factor 88 (MyD88)-deficiency increases risk of diabetes in mice. PLOS ONE 5, 9 (2010). 


\section{ARTICLES}

47. Subramanian, M, Ozcan, L, Ghorpade, DS, Ferrante, AW Jr. \& Tabas, I. Suppression of adaptive immune cell activation does not alter innate immune adipose inflammation or insulin resistance in obesity. PLOS ONE 10, e0135842 (2015).

48. Everard, A et al. Intestinal epithelial MyD88 is a sensor switching host metabolism towards obesity according to nutritional status. Nat. Commun. 5, 5648 (2014).

49. Yu, M et al. MyD88-dependent interplay between myeloid and endothelial cells in the initiation and progression of obesity-associated inflammatory diseases. J. Exp. Med. 211, 887-907 (2014).
50. Afrazi, Aetal. Toll-like receptor 4-mediated endoplasmic reticulum stress in intestinal crypts induces necrotizing enterocolitis. J. Biol. Chem. 289, 9584-9599 (2014).

51. Van Heek, $\mathrm{M}$ et al. Diet-induced obese mice develop peripheral, but not central, resistance to leptin. J. Clin. Invest. 99, 385-390 (1997).

52. Johnson, DH, Narayan, S, Wilson, DL \& Flask, CA. Body composition analysis of obesity and hepatic steatosis in mice by relaxation compensated fat fraction (RCFF) MRI. J. Magn. Reson. Imaging 35, 837-843 (2012).

53. Beguinot, $F \&$ Nigro, $C$. Measurement of glucose homeostasis in vivo: glucose and insulin tolerance tests. Methods Mol. Biol. 933, 219-228 (2012). 